

\section{Sumário}

I. Crônicas do Direito Internacional .................................................1

AMAZONIE: LE DROIT INTERNATIONAL EN VIGUEUR APPORTE DES RÉPONSES SUBSTANTIELLES ... 3 Pierre-Marie Dupuy

A eVOluÇão da SOluÇão DE CONTROVÉRSias NOS ACFIs 8 Ana Rachel Freitas da Silva

II. Dossiê Especial: Direito ambientai 14

A brief overview of Sustainable DeVelopment: HOW A DEBATEd CONCEPT With A MUCH-CONTESTED LEGAL NATURE COULD PERFORM A VALUABLE ROLE IN THE DECISION-MAKING ......16 Natali Francine Cinelli Moreira

A meta 11 de Aichi e as Áreas marinhas protegidas em grande ESCALA: proteção ambienTAL OU OPORTUNISMO POLÍTICO?

Alexandre Pereira da Silva

LITIGÂNCIA CLIMÁTICA COMO ESTRATÉGIA JURISDICIONAL AO AQUECIMENTO GLOBAL ANTROPOGÊNICO E MUDANÇAS CLIMÁTICAS

Délton Winter de Carvalho e Kelly de Souza Barbosa

AsSESSMENT AND CHALlENGES OF CARBON MARKETS

Louise Pigeolet e Arnaud Van Waeyenberge

As abordagens dos países da América Latina e Caribe sobre a mobilidade humana proVOCADA PELAS MUDANÇAS CLIMÁTICAS

Diogo Andreola Serraglio e Heline Sivini Ferreira

Implementation of Legal mechanisms of environmental protection by the South PaCIFIC REGIONAL ORGANIZATIONS 116 Joanna Siekiera 
CONCILIATING THE OVERLAP OF PROTECTED AREAS AND TRADITIONAL TERRITORIES: LEGAL INNOVATIONS FOR BIOLOGICAL DIVERSITY CONSERVATION IN BRAZILIAN PARKS

Nathalia Fernandes Lima e Solange Teles Silva

O USO DE DRONES COMO INSTRUMENTO PARA A CONSERVAÇÃo DA BIODIVERSIDADE NO BRASIL141 Larissa Suassuna Carvalho Barros e Marcia Dieguez Leuzinger

Agrotóxicos e direitos humanos no contexto global: o Brasil EM Risco de Retrocesso?

Marcelo Pretto Mosmann, Letícia Albuquerque e Isabele Bruna Barbieri

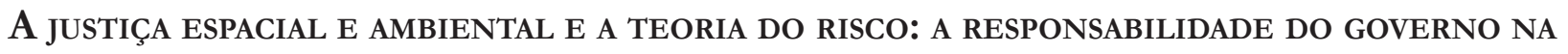
PREVENÇÃo CONTRA DESASTRES (NO BRASIL). 169

José Adércio Leite Sampaio e Edson Rodrigues de Oliveira

The judgment of the case Xucuru People v. Brazil: Inter-American Court of Human RigHTS BETWEEN CONSOLIDATION AND SETBACKS

Gabriela Cristina Braga Navarro

II. Artigos sobre outros temas

NACIONALIDADE: NOVAS REGRAS, VELHOS PROBLEMAS

226

Paulo Henrique Faria Nunes

O EXERCíCIO DA JURISDIÇÃO INTERAMERICANA DE DIREITOS HUMANOS: LEGITIMIDADE, PROBLEMAS E POSSÍVEIS SOLUÇÕES

Felipe Grizotto Ferreira, Guilherme Perez Cabrale Lucas Catib de Laurentiis

A proteção da identidade de gênero na jurisprudênCia da Corte Europeia de Direitos Humanos

Gabriel Coutinho Galil

O COMITÊ JURÍdico INTERAMERICANO dA OEA E A CODIFICAÇÃo DO DIREITO INTERNACIONAL REGIONAL. 
O caso Petruhhin e o princípio do nível mais elevado de proteção no tocante aos diREITOS FUNDAMENTAIS NO ÂMBITO DA UNIÃo EUROPEIA............................................304

Clovis Demarchi e Jaine Cristina Suzin

A AUTONOMia da VONTADE NA ESCOLHA dA LEI APLICÁVEl AOS CONTRATOS DE COMÉRCiO INTER-

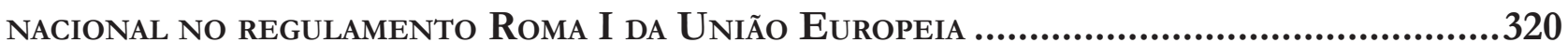

Aline Beltrame de Moura e Rafaela Hörmann

A JuRisdição da ICANN: desafios atuais e Prospectivas futuras...............................335 Aziz Tuffi Saliba e Amael Notini Moreira Bahia

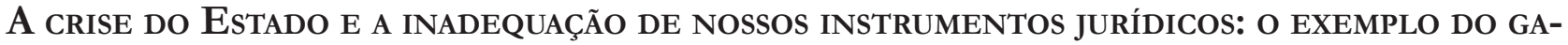
RANTISMO PENAL NO BRASIL.

Oswaldo Poll Costa e Francisco Quintanilha Veras Neto

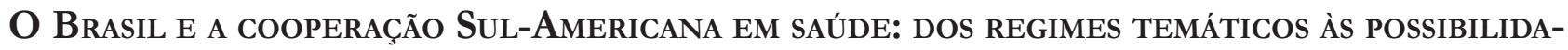
DES DE EFETIVAÇÃo ESTRUTURANTE

Ademar Pozzatti Junior e Luiza Witzel Farias

III. RESENHAS

Resenha da obra: SILVA, Waldimeiry Correa da. Regime internacional de enfrentaMENTO AO TRÁFICO DE PESSOAS: AVANÇOS E DESAFIOS PARA A PROTEÇÃo DOS DIREITOS HUMANOS. Rio de Janeiro: Lumen Juris, 2018. 385

Mércia Cardoso de Souza e Guirino Nhatave 


\title{
Litigância climática como estratégia jurisdicional ao aquecimento global antropogênico e mudanças climáticas*
}

\author{
Climate litigation as a jurisdictional strategy \\ to global anthropogenic heating and climate \\ change
}

\author{
Litigancia climática como estrategia \\ jurisdiccional al calentamiento global \\ antropogénico y cambios climáticos
}

\author{
Délton Winter de Carvalho** \\ Kelly de Souza Barbosa***
}

\section{Resumo}

* Recebido em 27/02/2019

Aprovado em 21/08/2019

** Graduado pela Universidade do Vale do Rio dos Sinos (1999). Mestre (2001) e Doutor (2006) em Direito pela Universidade do Vale do Rio dos Sinos. Pós-Doutor em Direito Ambiental e Direito dos Desastres pela University of California, Berkeley, CA, USA (2013), sob a orientação de Daniel A. Farber. Atualmente é Professor Adjunto I no Programa de Pós-Graduação em Direito - PPGD da Universidade do Vale do Rio dos Sinos. Membro da Associação Brasileira dos Professores de Direito Ambiental - APRODAB e do Instituto o Direito por um Planeta Verde. Membro do Conselho Editorial da Revista Brasileira de Direito Ambiental e da Revista Direito Ambiental e Sociedade. Líder do Grupo de Pesquisa Direito, Risco e Ecocomplexidade. E-mail : delton@deltoncarvalho.com.br.

*** Doutoranda em Direito pela Universidade do Vale do Rio dos Sinos - UNISINOS, com bolsa CAPES/PROEX. Mestre em Direitos Coletivos e Cidadania pela Universidade de Ribeirão Preto - UNAERP, com bolsa CAPES/PROSUP (2018). Especialista em Direito Processual Civil e Processo Cautelar pela Universidade Cândido Mendes - UCAM / Instituto Prominas (2017). Bacharela em Direito pela Universidade do Estado de Minas Gerais - UEMG, Unidade Passos (2015). Membro do Grupo de Pesquisa Direito, Risco e Ecocomplexidade. Advogada. E-mail : kellydesouza04@gmail.com.
O aquecimento global e as mudanças climáticas decorrentes da interferência antropogênica são pautas universais que clamam uma discussão séria, urgente e eficaz, entre o Poder Público, as organizações internacionais, o setor científico e empresarial e a sociedade. Não há como perseverar a apatia para regulamentação, implementação e fiscalização das emissões de gases de efeito estufa e atenuação às mudanças climáticas. Nesse contexto, diante da omissão ou comedido ímpeto dos principais atores responsáveis pelo aquecimento global antropogênico, como a litigância climática pode contribuir para a mitigação e adaptação das mudanças climáticas? Tendo como objetivo geral apresentar um panorama sobre a litigância climática, foram desenvolvidos dois capítulos utilizando como estratégia metodológica a pesquisa descritiva aliada a investigação bibliográfica e documental. Ademais, a título de exemplo e em atenção a tradição, influência global e quantidade de processos relacionados a essa matéria nos Estados Unidos da América, se refletiu sobre os principais litígios climáticos da jurisdição norte-americana. A litigância climática apresenta-se como uma estratégia promissora para compelir e impulsionar as grandes empresas, industrias e, principalmente, o Poder Público em sua função legislativa e executiva, a assumirem e se responsabilizarem pelo controle e impactos do aquecimento global antropogênico e mudanças climáticas.

Palavras-chave: Gases de efeito estufa antropogênicos. Aquecimento global antropogênico. Mudanças climáticas. Litigância climática. 


\section{Abstract}

Global warming and climate change are resulting to the anthropogenic are universal guidelines that call for a series of urgent, effective actions between the government, international organizations, the scientific and business sector and society. There is no way to persevere apathy in the regulation, implementation, and monitoring of greenhouse gas emissions and attenuation of climate change. In this context, given the omission or moderated impetus of the main actors responsible for anthropogenic global warming, how can climate litigation contribute to the mitigation and adaptation of climate change? Having a general objective to present a panorama on the climatic litigation, two chapters were developed using as a methodological strategy the descriptive research allied to bibliographical and documentary research. In addition, it used as an example and in view of the tradition, global influence and number of processes related to this matter in the United States of America, it was reflected on the main climatic litigations of the North American jurisdiction. Climate litigation presents itself as a promising strategy to compel and impel large corporations, industries, and especially the Public Power in its legislative and executive function, to assume and take responsibility for the control and impacts of anthropogenic global warming and climate change.

Keywords: Anthropogenic greenhouse gases. Global warming. Climate changes. Climate litigation.

\section{Resumen}

El calentamiento global y los cambios climáticos derivados de la interferencia antropogénica son pautas universales que claman una discusión seria, urgente, eficaz, entre el Poder Público, las organizaciones internacionales, el sector científico y empresarial y la sociedad. No hay como perseverar la apatía en la regulación, implementación y fiscalización de las emisiones de gases de efecto invernadero y atenuación al cambio climático. En este contexto, ante la omisión o comedido ímpetu de los principales actores responsables del calentamiento global antropogénico, ¿cómo el litigio climático puede contribuir a la mitigación y adaptación del cambio climático? Teniendo como objetivo general presentar un panorama sobre el litigio climático, se han desar- rollado dos capítulos utilizando como estrategia metodológica la investigación descriptiva aliada a la investigación bibliográfica y documental. Además, a titulo del ejemplo y teniendo en vista la tradición, la influencia global y el número de juicios relacionados a este asunto en los Estados Unidos de América, se fue reflejado sobre los principales litigios climáticos de la jurisdicción de América del Norte. La lentitud climática se presenta como una estrategia prometedora para obligar a las grandes empresas, industrias y, principalmente, al Poder Público en su función legislativa y ejecutiva, a asumir y responsabilizarse por el control e impactos del calentamiento global antropogénico y los cambios climáticos.

Palavras-claves: Gases de efecto invernadero antropogênicos. Calentamiento global antropogênico. Cambios climáticos. Litigios climáticos.

\section{Introdução}

A negação da interferência humana caótica na emissão de gases de efeito estufa e, consequente, aquecimento global, é uma mutilação da própria história. $\mathrm{O}$ fenômeno das mudanças climáticas deixou de ser uma constatação científica distante, para se tornar um problema cotidiano, global e catastrófico.

No recente relatório publicado pelo Intergovernmental Panel On Climate Change - IPCC, constatou-se que o aquecimento global de $1,5^{\circ} \mathrm{C}$ pode causar alterações climáticas robustas. Cita-se o aumento da temperatura média na maioria das regiões terrestres e oceânicas (bigh confidence), extremos quentes na maioria das regiões habitadas (bigh confidence), precipitação intensa em várias regiões (medium confidence) e a probabilidade de déficits de seca e precipitação em algumas regiões (medium confidence). Ademais, aumenta os riscos para a saúde, meios de subsistência, segurança alimentar, abastecimento de água, segurança humana e crescimento econômico. Todos esses cenários tornar-se-ão ainda mais graves se a temperatura global alcançar $2^{\circ} \mathrm{C} .{ }^{1}$

A questão climática exige das grandes empresas, industrias, corporações, e, principalmente, do Poder

INTERGOVERNMENTAL PANEL ON CLIMATE CHANGE (IPCC). Summary for policymakers. In: Special report: global warming of $1,5^{\circ} \mathrm{C}$. Geneva: World Meteorology Organization, 2018. Disponível em: https://www.ipcc.ch/sr15/chapter/ summary-for-policy-makers/. Acesso em: 29 jan. 2019. 
Público (em sua função administrativa e normativa), agirem para a contenção do problema e dos efeitos negativos que ele causou, causa e causará ao meio ambiente e à humanidade. A apatia precisa impreterivelmente ser enfrentada para que o aquecimento global não alcance (e, na pior das hipóteses, ultrapasse) $1,5^{\circ} \mathrm{C}$ acima dos níveis pré-industriais.

Nesse contexto, diante da omissão ou comedido ímpeto dos principais atores responsáveis pelo aquecimento global antropogênico, como a litigância climática pode contribuir para a mitigação e adaptação das mudanças climáticas?

Para perquirir e refletir sobre a problemática proposta, optou-se por utilizar a estratégia de pesquisa descritiva aliada à investigação bibliográfica (obras e artigos científicos nacionais e internacionais) e documental (tratados e convenções internacionais, relatórios técnico-científicos, precedentes jurisprudenciais, entre outros). Oportuno esclarecer que os cases climáticos exemplificativos abordados nesse ensaio pertencem à jurisdição norte-americana, tendo em vista o histórico, a experiência e a grande concentração de processos relacionados com essa temática nos Estados Unidos da América, os quais acabam por influenciar, direta e indiretamente, outras jurisdições e pesquisas científicas (sobretudo, do campo jurídico) ao redor do mundo.

Traçado o objetivo geral de explorar a emergente estratégia da litigância climática como instrumento impulsionador de modificações no tratamento político e jurídico das questões envolvendo o aquecimento global e as mudanças climáticas, foram desenvolvidos dois capítulos.

O primeiro capítulo foi dedicado à contextualização da relação entre a emissão de gases de efeito estufa antropogênicos (ou seja, aqueles emitidos exponencialmente pela atividade humana), o aquecimento global desgovernado, as consequentes mudanças climáticas e os impactos na humanidade.

$\mathrm{Na}$ sequência, abordaram-se os principais aspectos da litigância climática (objeto, partes envolvidas, repercussão, entre outros), sendo ainda apresentado, no segundo capítulo, alguns dos mais importantes cases norte-americanos sobre a mudança do clima e as perspectivas futuras dessa estratégia.

A litigância climática apresenta-se como uma promissora estratégia impulsionadora de mudanças enérgi- cas a serem empreendidas pelos principais atores responsáveis pela continuação dos níveis de aumento do aquecimento global e implementação de medidas para a mitigação e adaptação as alterações climáticas.

\section{Aquecimento global antropogênico e mudanças climáticas}

A biosfera é um sistema organizado, complexo e inter-relacionado que diferencia o Planeta Terra dos demais astros do sistema solar. Ela corresponde ao conjunto de ecossistemas (via de regra, são identificados a litosfera, hidrosfera e a atmosfera) onde se encontra a diversidade de seres vivos e os meios sobre os quais eles se desenvolvem e interagem. Particularmente, a atmosfera terrestre corresponde à camada de gases que envolve a superfície do Planeta Terra, e, dentre as suas funções, está a regulação da temperatura e clima.

Para que o Planeta Terra não seja uma grande esfera de gelo, a temperatura média global de $14^{\circ} \mathrm{C}$ surge pela sinergia equilibrada entre a energia da radiação solar (raios ultravioletas) que entra na atmosfera e é absorvida pela superfície terrestre e a energia calorífica liberada pela superfície terrestre aquecida (raios infravermelhos) direcionada ao espaço. Parte dela, retida na atmosfera, é novamente refletida em direção à superfície terrestre pela ação das moléculas dos gases de efeito estufa (GEE). Quanto maior a concentração de gases de efeito estufa, mais quente ficará o sistema climático. ${ }^{2}$

Os gases de efeito estufa ${ }^{3}$ podem ser classificados como: (i) naturais, produzidos pela natureza em nível equilibrado e necessário para a manutenção de calor no Planeta, por exemplo, aqueles decorrentes das erupções vulcânicas; ou (ii) antropogênicos, produzidos pela ação humana, por exemplo, queima de combustíveis fósseis, desmatamento, degradação ambiental, aerossóis. Ao longo dos anos, vem se verificando um aumento exponencial da temperatura média do Planeta devido à sobrecarga e concentração de gases de efeito estufa no

CONTIPELLI, Ernani de Paula. Política internacional climática: do consenso científico à governança global. Direito e Desenvolvimento, João Pessoa, v. 9, n. 2, p. 83-94, ago./dez. 2018. Disponível em: https://periodicos.unipe.br/index.php/direitoedesenvolvimento/ article/view/644. Acesso em: 31 jan. 2019. p. 84.

3 Os principais gases de efeito estufa presentes na atmosfera são: o vapor de água (H2O), dióxido de carbono (CO2), óxido nitroso (N2O), metano (CH4) e ozônio (O3). 
meio ambiente, sobretudo do gás carbônico (CO2). É o fenômeno do aquecimento global.

Com a percepção da intensificação do aquecimento global, também foi se verificando que o fenômeno estava provocando alterações negativas no clima. As mudanças climáticas causavam e, caso não sejam controladas, poderão causar, impactos negativos nos sistemas humano, econômico e natural. Podem ser citados o (a/s): aumento da temperatura média global e do nível dos mares e oceanos, derretimento das calotas polares, eventos climáticos extremos (secas, inundações, entre outros), abruptas mudanças no clima (ondas de calor), intensificação de incêndios; aumento da vulnerabilidade social dos mais pobres, crescimento do número de refugiados ambientais, redução da produtividade de alimentos e agricultura, destruição de propriedades costeiras, salinização da água doce, extinção de espécies, limitação ao acesso e uso de recursos naturais pela indústria, crise econômica, aumento de pragas e doenças (humanas e animais), declínio da biodiversidade, entre outros. ${ }^{4}$

Os prejuízos decorrentes das mudanças climáticas são inúmeros. Smith e Shearman citam, em fluxograma, como danos, a propriedade: perdas de imóveis, animais e propriedades; danos à propriedade nacional e pública; danos aos assentamentos a beira-mar e na costa litorânea; perda na produtividade agrícola, pesqueira e pecuária; perda dos meios de sobrevivência, deslocamentos das pessoas e pobreza. E, como danos à saúde (diretos e indiretos): mortes e doenças relacionadas com o estresse térmico, eventos climáticos extremos, proliferação microbiana, deficiência nutricional, bem como pelas alterações na geografia e sazonalidade das doenças

\footnotetext{
4 CARVAlHO, Délton Winter de. Gestão jurídica ambiental. São Paulo: Revista dos Tribunais, 2017.

CONVENÇÃO SOBRE MUDANÇA DO CLIMA, 1992. Disponível em: https://cetesb.sp.gov.br/proclima/wp-content/uploads/sites/36/2014/08/convencaomudancadoclima.pdf. Acesso em: 02 jan. 2019.

FARBER, Daniel A.; CARLARNE, Cinnamon P. The international climate change regime. In: Climate change law. St. Paul: Foundation Press, 2018. cap. 3.

INTERGOVERNMENTAL PANEL ON CLIMATE CHANGE (IPCC). Summary for policymakers. In: Special report: global warming of $1,5^{\circ} \mathrm{C}$. Geneva: World Meteorology Organization, 2018. Disponível em: https://www.ipcc.ch/sr15/chapter/summary-forpolicy-makers/. Acesso em: 29 jan. 2019.

OBSERVATÓRIO DO CLIMA. Emissões de GEE no Brasil e suas implicações para políticas públicas e a contribuição brasileira para o Acordo de Paris: documento de análise 2018. Brasil, SEEG, 2018. Disponível em: http://seeg.eco.br/wp-content/uploads/2018/08/RelatoriosSEEG-2018-Sintese-FINAL-v1.pdf. Acesso em: 31 jan. 2019.
}

infecciosas (risco de epidemias), entre outros riscos à saúde física e mental. ${ }^{5}$

As razões para o aumento do aquecimento global e a ocorrência das mudanças climáticas oscilavam entre aqueles que acreditavam ser esse um fenômeno predominantemente de causas naturais, aqueles que atribuíam, principalmente, a ação humana e aqueles céticos acerca da ocorrência de mudanças no clima. ${ }^{6}$

Os estudos sobre mudanças climáticas remontam ao século XIX, destacando a obra Teoria Analítica do Calor do matemático e cientista francês Jean Babtiste Joseph Fourier (1768-1830), nela principia a ideia de que a atmosfera exercia influência a temperatura planetária. Em 1896, o vencedor do Nobel de Química Svante Arrehenius (1859-1927) argumentou, em seus estudos sobre a influência do dióxido de carbono na atmosfera e as mudanças climáticas, já prevendo que o aumento da concentração desse gás poderia aumentar a temperatura do planeta. ${ }^{7}$

No entanto, entre 1900-1940, a Teoria do Dióxido de Carbono e a relação entre a concentração desse gás e o aquecimento global perdeu a sua força. Tal advertência pode ser verificada nas conclusões do físico Knut Angström de que toda a radiação infravermelha absorvida pelo gás carbônico também seria realizada pelo vapor de água. Outros cientistas também seguiram essa linha de raciocínio, desacreditando no aquecimento global em razão da alta concentração de gás carbônico. Alguns argumentavam que \begin{tabular}{l}
\hline SMITH, Joseph; SHEARMAN, David. An introduction to cli- \\
mate change litigation. In: Climate Change Litigation. Australia: Presid- \\
an Legal Publications, 2006. cap. 1. p. 9. \\
6 Para aprofundamento do tema vide BRASIL, Alexandre Luis \\
Junges; BRASIL, Neusa Teresinha Massoni. O consenso científico \\
sobre aquecimento global antropogênico: considerações históricas \\
e epistemológicas e reflexões para o ensino dessa temática. Revista \\
Brasileira de Pesquisa em Educação em Ciências, Belo Horizonte, v. 18, n. \\
2, p. 455-491, maio/ago. 2018. Disponível em: https://seer.ufmg. \\
br/index.php/rbpec/article/view/10345. Acesso em: 02 jan. 2019. \\
7 BRASIL, Alexandre Luis Junges; BRASIL, Neusa Teresinha \\
Massoni. O consenso científico sobre aquecimento global an- \\
tropogênico: considerações históricas e epistemológicas e reflexões \\
para o ensino dessa temática. Revista Brasileira de Pesquisa em Educação \\
em Ciências, Belo Horizonte, v. 18, n. 2, p. 455-491, maio/ago. 2018. \\
Disponível em: https://seer.ufmg.br/index.php/rbpec/article/ \\
view/10345. Acesso em: 02 jan. 2019. p. 463-471. \\
CONTIPELLI, Ernani de Paula. Política internacional climática: \\
do consenso científico à governança global. Direito e Desenvolvimento, \\
João Pessoa, v. 9, n. 2, p. 83-94, ago./dez. 2018. Disponível em: \\
https://periodicos.unipe.br/index.php/direitoedesenvolvimento/ \\
article/view/644. Acesso em: 31 jan. 2019. p. 86-91.
\end{tabular} 
o CO2 presente na atmosfera já exerceria a sua plena capacidade de absorção de radiação, de modo que um acréscimo de CO2 não aumentaria o efeito estufa. Finalmente, outros objetavam que o CO2 proveniente de emissões humanas ou vulcânicas seria rapidamente absorvido pelos oceanos. ${ }^{8}$

Sem obstar os outros cientistas que contribuíram com pesquisas acerca da existência ou não da relação entre o aumento da concentração de gás carbônico e a elevação da temperatura média global, salienta-se o estudo do oceanógrafo Charles Keeling (1928-2005) para a medição da concentração de gás carbônico na atmosfera. O cientista realizou medições no Polo Sul e nas ilhas havainas constatando que os oceanos não absorviam os excessos de emissão de gás carbônico (Curva de Keeling). Na década de 1980, novas pesquisas (e em maior número e uso de tecnologia e dados) surgem reforçando a influência antropogênica na temperatura mundial com a emissão de gás carbônico. No ano de 1979, a Organização Meteorológica Mundial (World Meteorological Organization - WMO) e o Conselho Internacional de Ciência (International Council for Science - ICSU) realizaram, em Genebra, a Primeira Conferência do Clima. Para organizar as pesquisas climáticas e apresentar mais segurança nas informações, a Organização Meteorológica Mundial e o Programa das Nações Unidas para o Meio Ambiente criaram o Painel Intergovernamental sobre Mudanças Climáticas (Intergovernmental Panel on Climate Change - IPCC). ${ }^{?}$

Corroborando os relatórios anteriores sobre a influência significativa das emissões de gases de efeito estufa antropogênicos no aquecimento global e mudanças climáticas, o IPCC divulgou em 2018 novo relatório no

\footnotetext{
BRASIL, Alexandre Luis Junges; BRASIL, Neusa Teresinha Massoni. O consenso científico sobre aquecimento global antropogênico: considerações históricas e epistemológicas e reflexões para o ensino dessa temática. Revista Brasileira de Pesquisa em Educação em Ciências, Belo Horizonte, v. 18, n. 2, p. 455-491, maio/ago. 2018. Disponível em: https://seer.ufmg.br/index.php/rbpec/article/ view/10345. Acesso em: 02 jan. 2019. p. 463-465.

9 BRASIL, Alexandre Luis Junges; BRASIL, Neusa Teresinha Massoni. O consenso científico sobre aquecimento global antropogênico: considerações históricas e epistemológicas e reflexões para o ensino dessa temática. Revista Brasileira de Pesquisa em Educação em Ciências, Belo Horizonte, v. 18, n. 2, p. 455-491, maio/ago. 2018. Disponível em: https://seer.ufmg.br/index.php/rbpec/article/ view/10345. Acesso em: 02 jan. 2019. p. 463-471.

CONTIPELLI, Ernani de Paula. Política internacional climática: do consenso científico à governança global. Direito e Desenvolvimento, João Pessoa, v. 9, n. 2, p. 83-94, ago./dez. 2018. Disponível em: https://periodicos.unipe.br/index.php/direitoedesenvolvimento/ article/view/644. Acesso em: 31 jan. 2019. p. 86-91.
}

qual se estimou que as atividades humanas causaram, aproximadamente, $1,0^{\circ} \mathrm{C}$ de aquecimento global acima do nível pré-industrial ${ }^{10}$, com um intervalo provável ( $l$ kely) de $0,8^{\circ} \mathrm{C}$ a $1,2^{\circ} \mathrm{C}$. Caso continue aumentando a taxa de emissões, a confiança é alta (high confidence) de que o aquecimento global provavelmente (likely) atinja $1,5^{\circ} \mathrm{C}$ entre 2030 e $2052 .^{11}$

Refletindo a tendência de aquecimento de longo prazo desde os tempos pré-industriais, a temperatura da superfície média global observada (GMST) para a década de $2006-2015$ foi de $0,87^{\circ} \mathrm{C}$ (provavelmente entre $0,75^{\circ} \mathrm{C}$ e $0,99^{\circ} \mathrm{C}$ ) maior do que a média durante o período de 1850-1900 (confiança muito alta). $\mathrm{O}$ aquecimento global antropogênico estimado corresponde ao nível de aquecimento observado a $\pm 20 \%$ (faixa provável). O aquecimento global antropogênico estimado está aumentando atualmente a $0,2^{\circ} \mathrm{C}$ (provavelmente entre $0,1^{\circ} \mathrm{C}$ e 0,3 $\left.{ }^{\circ} \mathrm{C}\right)$ por década devido a emissões passadas e atuais (alta confiança). ${ }^{12}$

Ainda, segundo esse relatório, há alta confiança (bigh cofidence) de que algumas regiões do mundo já possuem um aquecimento maior do que a média anual global, e essa alteração geralmente é maior na terra do que no oceano. Da mesma forma, existe alta confiança (bigh cofidence) de que os sistemas naturais e humanos já sofreram impactos com o aquecimento global. A confiança tam-

10 Segundo o IPCC, o período pré-industrial corresponde ao período de vários séculos antes do início da atividade industrial em grande escala ocorrido por volta do ano de 1750, sendo utilizado o período de referência 1850-1900 para aproximar a temperatura média global da superfície (Global mean surface temperature - GMST) préindustrial. INTERGOVERNMENTAL PANEL ON CLIMATE CHANGE (IPCC). Summary for policymakers. In: Special report: global warming of $1,5^{\circ} \mathrm{C}$. Geneva: World Meteorology Organization, 2018. Disponível em: https://www.ipcc.ch/sr15/chapter/ summary-for-policy-makers/. Acesso em: 29 jan. 2019.

11 INTERGOVERNMENTAL PANEL ON CLIMATE CHANGE (IPCC). Summary for policymakers. In: Special report: global warming of $1,5^{\circ} \mathrm{C}$. Geneva: World Meteorology Organization, 2018. Disponível em: https://www.ipcc.ch/sr15/chapter/ summary-for-policy-makers/. Acesso em: 29 jan. 2019.

12 Versão original: "Reflecting the long-term warming trend since pre-industrial times, observed global mean surface temperature (GMST) for the decade $2006-2015$ was $0.87^{\circ} \mathrm{C}$ (likely between $0.75^{\circ} \mathrm{C}$ and $0.99^{\circ} \mathrm{C}$ ) higher than the average over the $1850-1900$ period (very high confidence). Estimated anthropogenic global warming matches the level of observed warming to within $\pm 20 \%$ (likely range). Estimated anthropogenic global warming is currently increasing at $0.2^{\circ} \mathrm{C}$ (likely between $0.1^{\circ} \mathrm{C}$ and $0.3^{\circ} \mathrm{C}$ ) per decade due to past and ongoing emissions (high confidence)." INTERGOVERNMENTAL PANEL ON CLIMATE CHANGE (IPCC). Summary for policymakers. In: Special report: global warming of $1,5^{\circ} \mathrm{C}$. Geneva: World Meteorology Organization, 2018. Disponível em: https://www.ipcc.ch/sr15/chapter/summary-for-policy-makers/. Acesso em: 29 jan. 2019. 
bém é alta (high cofidence) de que os riscos para os referidos sistemas serão maiores caso o aquecimento global alcance $1,5^{\circ} \mathrm{C}$ em comparação com a temperatura atual, mas, ainda assim, menores se for considerado o cenário de $2^{\circ} \mathrm{C}$ acima dos níveis pré-industriais. ${ }^{13}$

Ademais, nas análises mais recentes das observações feitas no âmbito do Programa de Vigilância da Atmosfera Global (Programa VAG) e Organização Meteorológica Mundial, publicadas no Boletim sobre os gases de efeito estufa de novembro de 2018, além do aumento inesperado das emissões mundiais de CFC-11 ${ }^{14}$, verificou-se que:

[A]s médias mundiais das frações molares em superfície calculadas a partir desta rede in situ para o dióxido de carbono (CO2), o metano (CH4) e o óxido nitroso (N2O) alcançaram novos máximos em 2017 ao registrar 405,5 $\pm 0,1 \mathrm{ppm}$ [partes por milhão] para o CO2, $1859 \pm 2 \mathrm{ppb}$ [partes por bilhão] para o CH4 e 329,9 \pm 0,1 ppb para o N2O, o que representa, respectivamente, $146 \%, 257 \% \mathrm{e}$ $122 \%$ dos níveis pré-industriais (antes de 1750). ${ }^{15}$

13 INTERGOVERNMENTAL PANEL ON CLIMATE CHANGE (IPCC). Summary for policymakers. In: Special report: global warming of $1,5^{\circ} \mathrm{C}$. Geneva: World Meteorology Organization, 2018. Disponível em: https://www.ipcc.ch/sr15/chapter/ summary-for-policy-makers/. Acesso em: 29 jan. 2019.

14 "As medições da abundância atmosférica de CFC-11 (triclorofluorometano ou CCl3F), um potente gás de efeito estufa (GEE) e substância que esgota a camada de ozônio estratosférico regulada pelo Protocolo de Montreal sobre as substâncias que destroem a camada do ozono, mostram que, desde 2012, a taxa de diminuição do CFC-11 desacelerou para cerca de dois terços em relação à década anterior. A causa mais provável deste ritmo de diminuição mais lenta é a maior quantidade de emissões ligadas à produção de CFC11 na Ásia oriental."

Versão original: "Las mediciones de la abundancia atmosférica de CFC-11 (triclorofluorometano o $\mathrm{CCl} 3 \mathrm{~F}$ ), un potente gas de efecto invernadero (GEI) y sustancia que agota la capa de ozono estratosférico regulado en el marco del Protocolo de Montreal relativo a las sustancias que agotan la capa de ozono, muestran que desde 2012 la tasa de disminución de CFC-11 se ha lentificado aproximadamente a dos terceras partes con respecto al decenio anterior. La causa más probable de este ritmo de disminución más lento es la mayor cantidad de emisiones vinculadas a la producción de CFC-11 en Asia oriental". ORGANIZACIÓN METEOROLÓGICA MUNDIAL (OMM). Boletín de la OMM sobre los gases de efecto invernadero. n. 14. Genebra: OMM, 22 nov. 2018. Disponível em: https://library.wmo. int $/$ index.php?lvl=notice_display\&id $=6887 \# . X F g D 0 V x K h P Y$. Acesso em: 04 jan. 2019.

15 Versão original: “[...] los promedios mundiales de las fracciones molares en superficie1) calculados a partir de esta red in situ para el dióxido de carbono (CO2), el metano (CH4) y el óxido nitroso (N2O), alcanzaron nuevos máximos en 2017 al registrar 405,5 \pm $0,1 \mathrm{ppm}$ para el CO2, $1859 \pm 2 \mathrm{ppb} 3)$ para el CH4 y $329,9 \pm 0,1$ ppb para el N2O, lo que representa, respectivamente, el $146 \%$, el $257 \%$ y el $122 \%$ de los niveles preindustriales (antes de 1750)." ORGANIZACIÓN METEOROLÓGICA MUNDIAL (OMM).
A constatação científica de que as mudanças climáticas têm como responsável a influência antropogênica na atmosfera, bem como os resultados e prognósticos catastróficos desse fenômeno no mundo, fizeram com que organizações internacionais, Estados-nação e indivíduos se atentassem à temática. Segundo Farber e Carlarne ${ }^{16}$, o regime internacional de mudanças climáticas possui três instrumentos primários de lei internacional, são eles: Convenção-Quadro das Nações Unidas sobre a Mudança do Clima, Protocolo de Quioto e Acordo de Paris.

No ano de 1992, na cidade do Rio de Janeiro (Brasil), foi realizada a Conferência das Nações Unidas para o Meio Ambiente e o Desenvolvimento (notadamente conhecida como Rio-92, Cúpula da Terra) que reuniu 178 delegações (incluindo chefes de Estado e de Governo) de 115 países para criarem uma agenda global sobre as questões ambientais mundiais. Criada durante a Rio92, entrou em vigor no dia 21 de março de 1994 a Convenção-Quadro das Nações Unidas sobre a Mudança do Clima ${ }^{17}$. Tal Convenção foi ratificada por 196 Partes (Estados) que assumiram o compromisso de estabilizarem a concentração de gases de efeito estufa antropogênicos na atmosfera, a fim de evitarem a interferência humana danosa no sistema climático do mundo. ${ }^{18}$

Boletin de la OMM sobre los gases de efecto invernadero. n. 14. Genebra: OMM, 22 nov. 2018. Disponível em: https://library.wmo.int/index. php?lvl=notice_display\&id=6887\#.XFgD0VxKhPY. Acesso em: 04 jan. 2019.

16 FARBER, Daniel A.; CARLARNE, Cinnamon P. The international climate change regime. In: Climate change law. St. Paul: Foundation Press, 2018. cap. 3. p. 57.

17 Segundo Biato na Convenção-Quadro das Nações Unidas sobre a Mudança do Clima “[a]dotou-se uma Convenção geral que estabelece princípios e instituições, e permite o início de um processo de negociação. Depois, à medida que os conhecimentos científicos fossem aprofundados, as Partes adotariam protocolos e ajustes para aperfeiçoar os procedimentos.” BIATO, Márcia Fortuna. Convenção-quadro das Nações Unidas sobre mudança do clima. Revista de Informação Legislativa, Brasília, a. 42, n. 166, p. 233-252, abr./jun. 2005. Disponível em: http://egov.ufsc.br/portal/sites/default/ files/anexos/22129-22130-1-PB.pdf. Acesso em: 26 fev. 2019. p. 239.

18 BIATO, Márcia Fortuna. Convenção-quadro das Nações Unidas sobre mudança do clima. Revista de Informação Legislativa, Brasília, a. 42, n. 166, p. 233-252, abr./jun. 2005. Disponível em: http://egov. ufsc.br/portal/sites/default/files/anexos/22129-22130-1-PB.pdf. Acesso em: 26 fev. 2019.

ORGANIZAÇÃO DAS NAÇÕES UNIDAS (ONU). Conferência das Nações Unidas sobre mudança do clima. Brasil, 2018. Disponível em: https://nacoesunidas.org/cop21/. Acesso em: 26 fev. 2019.

CONVENÇÃO SOBRE MUDANÇA DO CLIMA, 1992. Disponível em: https://cetesb.sp.gov.br/proclima/wp-content/uploads/sites/36/2014/08/convencaomudanca 
Quioto (Japão) foi o local escolhido para serem discutidas e negociadas no ano de 1997 metas mais efetivas para a redução da emissão de gases de efeito estufa a fim de combater e aliviar os impactos do aquecimento global. No ano de 2005, o Protocolo de Quioto ${ }^{19}$ (1997) entrou em vigor após a ratificação dos 55 países que juntos produziam 55\% das emissões antropogênicas mundiais. Dentre os compromissos, destacam-se a obrigação das Partes, principalmente aquelas tidas como desenvolvidas, para a redução ao menos de $5 \%$ dos níveis de emissão de gases de efeito estufa em comparação aos níveis de 1990, no período de 2008-2012, e a adoção pelos países em desenvolvimento aos Mecanismos de Desenvolvimento Limpo (MDL) ${ }^{20}$.

Em 2015, na 21ª Conferência das Partes (COP) da Convenção-Quadro das Nações Unidas sobre a Mudança Climática realizada em Paris (França), foi adotado um novo acordo entre as Partes para manter o aumento da temperatura média global em menos de $2^{\circ} \mathrm{C}$ acima dos níveis pré-industriais e promover esforços para limitar o aumento da temperatura a $1,5^{\circ} \mathrm{C}$. O Acordo de Paris $2015^{21}$ também reforça a necessidade do aumento nos

doclima.pdf. Acesso em: 02 jan. 2019.

19 Fonseca explica em nota de rodapé que "[e]mbora os protocolos sejam aplicados para interpretar ou implementar os objetivos do acordo principal, são instrumentos ratificados separadamente. Assim, há Estados que se vinculam ao acordo principal, sem, no entanto, se vincularem aos protocolos." FONSECA, Fúlvio Eduardo. A convergência entre a proteção ambiental e a proteção da pessoa humana no âmbito do direito internacional. Revista Brasileira de Politica Internacional, Rio de Janeiro, v. 50, n. 1, p. 121-138, 2007. Disponível em: http://www.scielo.br/pdf/rbpi/v50n1/a07v50n1. Acesso em: 26 fev. 2019. p. 126.

20 PROTOCOLO DE QUIOTO, 1997. Disponível em: http:// mudancasclimaticas.cptec.inpe.br/ rmclima/pdfs/Protocolo_Quioto.pdf. Acesso em: 02 jan. 2019.

21 Os Estados Unidos da América é um dos maiores emissores de gases de efeito estufa antropogênicos do mundo. Embora tenha assinado o Acordo de Paris, no ano de 2017 o Presidente Donald Trump anunciou que o país sairia do acordo. Farber e Carlarne pontuam que a decisão não tem efeito imediato, haja vista a previsão constante no artigo 28 do Acordo de Paris e as datas da próxima eleição presidencial. Ademais, outras partes do Acordo (como China e União Europeia) assinalam que a saída do Estado norte-americano não afetará o compromisso, no entanto, é o futuro que dirá se a vitalidade do Acordo de Paris foi ou não afetada. FARBER, Daniel A.; CARLARNE, Cinnamon P. The international climate change regime. In: Climate change law. St. Paul: Foundation Press, 2018. cap. 3. p. 72 . esforços para a mitigação ${ }^{22}$ e adaptação ${ }^{23}$, bem como para o financiamento climático, considerando o "princípio da igualdade e responsabilidades comuns, porém diferenciadas e respectivas capacidades, à luz das diferentes circunstâncias nacionais". ${ }^{24}$

Pesquisas científicas de distintas áreas, cientistas e organizações científicas renomadas de diversas partes do mundo, relatórios técnicos de ponta desenvolvidos sob critérios científicos rígidos e alta tecnologia, documentos internacionais e nacionais, entre outros, atestam e entram em consenso acerca da influência antropogênica no aquecimento global e nas mudanças climáticas. ${ }^{25}$

22 O IPCC define a mitigação (da mudança climática) como a intervenção humana para reduzir as emissões de gases de efeito estufa ou melhorar a forma de retirada (sumidouros, sinks) desses gases da atmosfera. INTERGOVERNMENTAL PANEL ON CLIMATE CHANGE (IPCC). Summary for policymakers. In: Special report: global warming of $1,5^{\circ} \mathrm{C}$. Geneva: World Meteorology Organization, 2018. Disponível em: https://www.ipcc.ch/sr15/chapter/ summary-for-policy-makers/. Acesso em: 29 jan. 2019.

23 O conceito de adaptação, segundo o IPCC: "Nos sistemas bumanos, o processo de ajuste real ou esperado ao clima e seus efeitos, a fim de moderar danos ou explorar oportunidades benéficas. Nos sistemas naturais, o processo de ajuste ao clima atual e seus efeitos; a intervenção humana pode facilitar o ajuste ao clima esperado e seus efeitos." (Tradução Nossa).

Versão original: "In buman systems, the process of adjustment to actual or expected climate and its effects, in order to moderate harm or exploit beneficial opportunities. In natural systems, the process of adjustment to actual climate and its effects; human intervention may facilitate adjustment to expected climate and its effects." INTERGOVERNMENTAL PANEL ON CLIMATE CHANGE (IPCC). Summary for policymakers. In: Special report: global warming of 1,5ㄷ. Geneva: World Meteorology Organization, 2018. Disponível em: https://www.ipcc.ch/sr15/chapter/summary-for-policy-makers/. Acesso em: 29 jan. 2019.

${ }^{24}$ ACORDO DE PARIS, 2015. Disponível em: https://nacoesunidas.org/wp-content/uploads/2016/04/Acordo-de-Paris.pdf. Acesso em: 02 jan. 2019.

25 A National Aeronautics and Space Administration (NASA), agência norte-americana responsável por projetos de exploração espacial, acompanha o entendimento científico de que os gases de efeito estufa emitidos pelas atividades humanas é uma das principais causas para as mudanças climáticas globais. Para ilustrar o consenso científico a respeito da interferência antropogênica no clima mundial, a agência elenca as seguintes organizações: (a) Associações científicas norte-americanas: Academias de Ciência respectivamente: American Association for the Advancement of Science, American Chemical Society, American Geophysical Union, American Medical Association, American Meteorological Society, American Physical Society, The Geological Society of America; (b) Academia de ciências: U.S. National Academy of Sciences; (c) Agência do Governo dos EUA: U.S. Global Change Research Program; (d) Órgão intergovernamental: Intergovernmental Panel on Climate Change. NATIONAL AERONAUTICS AND SPACE ADMINISTRATION (NASA). Scientific consensus: Earth's climate is warming. California: Earth Science Communications Team at NASA's Jet Propulsion Laboratory; California Institute of Technology, 2019. Disponível em: https://climate.nasa.gov/scientific-consensus/. Acesso 
Negar isso é desconsiderar a própria história e as investigações científicas desenvolvidas ao longo dos últimos séculos e que estão em progresso ${ }^{26}$.

Como assevera Nobre, a diferença entre a atual geração e a geração pós-guerra (momento em que houve um exponencial crescimento econômico, industrialização, exploração dos recursos naturais, aumento populacional) é a posse do conhecimento sobre as mudanças climáticas.

E por isso a responsabilidade maior de quem está construindo agora o planeta que será deixado para nossos descendentes. Se a trajetória não for alterada, a experiência humana relegará às gerações futuras um planeta num grau incomparavelmente maior de crise ambiental em relação às condições ambientais que recebemos de nossos pais. ${ }^{27}$

Todavia, a realidade demonstra que essa conscientização ainda é pequena diante da magnitude do problema e ela não deve estar concentrada apenas ao âmbito nacional ou internacional (transnacional), ou aos atores privados ou públicos. ${ }^{28} \mathrm{~A}$ atuação deve ser conjunta!

em: 27 fev. 2019.

A Office of Planning and Research (OPR), criada em 1970 e que integra o Escritório do Governador do Estado da Califórnia (EUA), também disponibiliza no link http://www.opr.ca.gov/facts/list-ofscientific-organizations.html uma lista com cerca de 200 (duzentas) organizações científicas mundiais que defendem a posição de que a ação humana interferiu no equilíbrio climático do mundo. OFFICE OF PLANNING AND RESEARCH (OPR). List of worldwide scientific organizations. California, 2019. Disponível em: http://www. opr.ca.gov/facts/list-of-scientific-organizations.html. Acesso em: 27 fev. 2019.

Ademais recomenda-se a leitura da obra US NATIONAL ACADEMY OF SCIENCES; THE ROYAL SOCIETY. Climate change: evidence \& causes. Washington: National Academy of Sciences, 2014. Disponível em: https://www.nap.edu/read/18730/chapter/1. Acesso em: 27 fev. 2019.

26 Sobre o ensino das mudanças climáticas vide BRASIL, Alexandre Luis Junges; BRASIL, Neusa Teresinha Massoni. O consenso científico sobre aquecimento global antropogênico: considerações históricas e epistemológicas e reflexões para o ensino dessa temática. Revista Brasileira de Pesquisa em Educação em Ciências, Belo Horizonte, v. 18, n. 2, p. 455-491, maio/ago. 2018. Disponível em: https:// seer.ufmg.br/index.php/rbpec/article/view/10345. Acesso em: 02 jan. 2019.

27 NOBRE, C. A. Mudanças climáticas e o Brasil: contextualização. Parcerias Estratégicas, Brasília, v. 27, p. 7-17, 2008. Disponível em: http://seer.cgee.org.br/index.php/parcerias_estrategicas/article/viewFile/326/320. Acesso em: 30 jan. 2019. p. 14.

28 Saint-Geniès explica que: "de qualquer forma, unidas ou fragmentadas, as soluções privadas para a crise climática nunca poderão substituir totalmente a ação pública coletiva, pois a resolução da crise climática é antes de mais nada uma questão de interesse geral. [...]. Ao mesmo tempo, na ausência de uma ação pública coletiva suficientemente ambiciosa e eficaz, a contribuição das normas privadas internacionais sobre o clima parece, mais do que nunca, necessária
Logo mostra-se importante o uso de novas estratégias para impulsionar (todos) os atores a verdadeiramente controlarem a emissão antropogênica de gases de efeito estufa e implementarem medidas de mitigação e adaptação climática, por exemplo, utilizando o processo judicial.

\section{Panorama da litigância climática}

A mudança do clima causada pelas emissões antropogênicas de gases de efeito estufa impõe ao indivíduo, sociedade, organizações, entidades e, principalmente, Poder Público a releitura de seus respectivos papéis e funções na melhoria do meio ambiente e/ou contenção das interferências nefastas a existência de vida.

Bernando alerta quanto à presença de uma certa resistência à implementação de medidas de mitigação da produção "humana" de gases de efeito estufa e adaptação aos novos cenários decorrentes da mudança climática. Ela pode ser verificada em alguns segmentos da sociedade e do setor econômico, uma vez que as medidas de mitigação e adaptação climática demandam interferências significativas nessas esferas (v.g. restrições ao padrão de consumo, na emissão de gases de efeito estufa), bem como podem ameaçar seus interesses (v.g. crescimento econômico, empregabilidade). Ademais, nota-se o comedimento na tomada de decisões drásticas por representantes eleitos aos poderes legislativo e executivo que possuem a legitimidade para a implementação dessas medidas, a fim de não desagradarem parte do eleitorado e garantir a reeleição. ${ }^{29}$

Nesse contexto, para romper a inércia e/ou indiferença de certos governantes, parlamentares e empresas privadas no real enfrentamento das ações potencialmente colaboradoras do aquecimento global, nota-se que o debate vem sendo transferido ao Poder Judiciário com a emergente litigância climática (climate change litigation),

para substituir um direito estatal cuja credibilidade frequentemente deixa a desejar." SAINT-GENIÈS, Géraud de Lassus. Direito transnacional e mudanças climáticas. Revista de Direito Internacional, Brasília, v. 13, n. 3, p. 49-61, 2016. Disponível em: https://www.publicacoesacademicas.uniceub.br/rdi/article/view/4377/pdf. Acesso em: 07 jul. 2019. p. 60.

29 BERNARDO, Vinicius Lameira. Mudanças climática: estratégia de litigância e o poder do judiciário no combate às causas do aquecimento global no contexto brasileiro. Revista de Direito Ambiental, Porto Alegre, a. 22, v. 88, p. 517-548, out./dez. 2017. p. 518-519. 
também denominada como litigância do clima.

A litigância climática visa impulsionar ações de controle e diminuição da emissão antropogênica de gases de efeito estufa, e demais medidas de contenção às mudanças climáticas. Pela via jurisdicional ${ }^{30}$, os atores públicos e privados (nacionais e internacionais) que emitem (ou permitem) significativamente esses gases poluentes seriam responsabilizados e/ou constrangidos a adotarem comportamentos mais ativos para o alcance do compromisso global de redução do efeito estufa.

O Programa das Nações Unidas para o Meio Ambiente destaca como causas para o crescente reconhecimento e uso da litigância climática, como estratégia contra as mudanças climáticas, o aumento da legislação sobre o tema e o Acordo de Paris. Vide abaixo o trecho transcrito que explica tal posicionamento.

\footnotetext{
Isso se deve em grande medida ao crescente número de legislação nacional que aborda a mudança climática, o que proporciona pontos de apoio para que os litigantes persigam atores governamentais e privados para que assumam suas responsabilidades e deveres de mitigar ou adaptar. Também se deve ao papel coerente que desempenha o Acordo de Paris, que coloca em um contexto global as leis e políticas nacionais e, por fim, permite que os litigantes interpretem os compromissos e ações governamentais como adequados ou inadequados. (Tradução nossa). ${ }^{31}$
}

30 Não obstante o foco desse trabalho esteja no papel do Poder Judiciário nas decisões em litígios climáticos, em estudo recente publicado pelo Programa das Nações Unidas para o Meio Ambiente em cooperação com o Sabin Center for Climate Change Law da Columbia Law School, verifica-se a ampliação da ideia de quais seriam as esferas decisionais nos cases climáticos, como se depreende do trecho transcrito a seguir. "Considera como 'litígio de mudança climática' aqueles casos que têm sido levados as instâncias administrativas, judiciais ou investigativas, que apresentam questões de fato ou de direito de aspectos científicos da mudança climática ou esforços de mitigação e adaptação a mudança climática.” (Tradução nossa).

Versão original: "Considera como "litigios del cambio climático" aquellos casos que han sido llevados ante instancias administrativas, judiciales o investigativas, que presentan cuestiones de hecho o de derecho de aspectos científicos del cambio climático o esfuerzos de mitigación y adaptación al cambio climático.” PROGRAMA DE LAS NACIONES UNIDAS PARA EL MEDIO AMBIENTE. E/ estado del litigio en materia de cambio climático: una revisión global. Nairobi: División Jurídica ONU Medio Ambiente, mayo 2017. p. 10.

31 Versão original: "La litigación ha surgido como una característica destacada de los esfuerzos en curso para fomentar las medidas de mitigación y adaptación al cambio climático. Esto se debe en gran medida al creciente número de legislación nacional que aborda directamente el cambio climático, lo que proporciona puntos de apoyo para que los litigantes persigan que actores gubernamentales y privados asuman su responsabilidad y deber de mitigar o adaptar. También se debe al papel coherente que desempeña el Acuerdo de
Carvalho caracteriza a litigância climática como uma forma de governança, pois estimula alterações no comportamento das instituições públicas e privadas e na forma como as decisões são tomadas, mesmo que a ação não seja procedente. Isso porque a simples propositura da ação repercute (in)diretamente na mudança de comportamento dos envolvidos ${ }^{32}$; por colocar em evidencia questão basilares à existência de vida no planeta, ela atrai o apelo midiático, popularizando a ação e o debate; por influenciar em outras políticas governamentais e corporativas para a adoção de medidas de redução dos impactos que suas atividades podem causar ao clima, tendo em vista a litigância em si e a expectativa de futuras demandas. ${ }^{33}$

Resenhando Jolene Lin, Boixareu e Calvó mencionam que, no contexto da litigância climática, os tribunais com frequência

se vêm forçados a determinar quais questões climáticas podem ser julgadas e sobre quais devem se inibir em favor dos outros poderes do Estado. Isso precisamente porque grande parte da litigação climática surge dos limites e fracassos da política institucional como método cidadão de pressão política. $^{34}$

Destarte, importante o alerta de Bernardo quanto aos limites do Poder Judiciário ao exercer sua função

París, que coloca en un contexto global a leyes y políticas nacionales $\mathrm{y}$, por ende, permite que los litigantes interpreten los compromisos y acciones gubernamentales como adecuados o inadecuados." PROGRAMA DE LAS NACIONES UNIDAS PARA EL MEDIO AMBIENTE. El estado del litigio en materia de cambio climático: una revisión global. Nairobi: División Jurídica ONU Medio Ambiente, mayo 2017. p. 40.

32 Analogicamente vide a mudança de comportamento da indústria tabagista, com as ações de responsabilização em razão dos problemas de saúde causados pelo uso do produto $(v \cdot g$. câncer).

33 CARVALHO, Délton Winter de. Uma incursão sobre a litigância climática: entre mudança climática e responsabilidade civil. In: MIRANDA, Jorge; GOMES, Carla Amado (coord.). Diálogo ambiental, constitucional e internacional. Lisboa: Faculdade de Direito de Lisboa; OH! Multimédia, 2017. v. 6. p. 95-118. Disponível em: http://www. icjp.pt/sites/default/files/publicacoes/files/ebook_dialogoambiental_6_3-18.pdf. Acesso em: 28 jan. 2019.p. 101.

34 Versão original: “[...] se ven forzados a determinar qué cuestiones climáticas pueden entrar a juzgar y sobre cuáles deben inhibirse en favor de otros poderes del Estado. Ello precisamente porque gran parte de la litigación climática surge de los límites y fracasos de la política institucional como método ciudadano de presión política”. BOIXAREU, Isabel Vilaseca; CALVÓ, Jordi Serra. Litigación climática y separación de poderes: uma aproximación a la cuestión a través de decisiones judiciales de los Estados Unidos. Revista Catalana de Dret Ambiental, Catalunya, v. 9, n. 2, p. 01-42, 2018. Disponível em: https://revistes.urv.cat/index.php/rcda/article/ view/2182/2452. Acesso em: 26 jan. 2019. p. 5-6. 
institucional no âmbito da litigância climática ${ }^{35}$, uma vez que o Princípio da Separação dos poderes deve ser respeitado na tomada de decisão e, acrescenta-se. Por exemplo, "estabelecer limites as emissões obrigatórias ${ }^{36}$ para grandes poluidores ou setores específicos da sociedade vai além de suas capacidades, e deve ser deixado para os demais poderes da república." O que não obsta que o magistrado pressione os governantes e parlamentares a tomarem medidas efetivas e mais elaboradas contra as alterações climáticas e que no processo de tomada de decisão desses poderes a questão climática seja levada em consideração. Ademais, parafraseando Brian Preston, o autor explica que, mesmo quando o cidadão se sinta excluído no processo de tomada de decisão legislativa e executiva, as decisões judiciais podem criar um espaço para que o debate entre o Poder Público, sociedade civil e empresários seja feito em igualdade de condições. ${ }^{37}$

A litigância climática não é uma estratégia altruísta, espontânea e sem regras. O Programa das Nações Unidas para o Meio Ambiente adverte que nos litígios de mudanças climáticas os envolvidos (partes do processo e o juiz) devem estar atentos às condições de justiciabilidade, direito de ação e separação dos poderes. ${ }^{38}$

Os potenciais autores da demanda climática são os indivíduos, grupos de interesse público e governos, que

\footnotetext{
35 Os Estados Unidos da América concentram o maior número de litígios climáticos no mundo, de modo que seus precedentes inspiram (e influenciam) as jurisdições não norte-americanas. Por certo, isso também repercute nas discussões em torno dos limites e da competência jurisdicional em matéria climática. Logo recomenda-se a leitura da monografia BOIXAREU, Isabel Vilaseca; CALVÓ, Jordi Serra. Litigación climática y separación de poderes: uma aproximación a la cuestión a través de decisiones judiciales de los Estados Unidos. Revista Catalana de Dret Ambiental, Catalunya, v. 9, n. 2, p. 01 42, 2018. Disponível em: https://revistes.urv.cat/index.php/rcda/ article/view/2182/2452. Acesso em: 26 jan. 2019.

36 Vide o caso Connecticut v. American Eletric Power Corporation.

37 BERNARDO, Vinicius Lameira. Mudanças climática: estratégia de litigância e o poder do judiciário no combate às causas do aquecimento global no contexto brasileiro. Revista de Direito Ambiental, Porto Alegre, a. 22, v. 88, p. 517-548, out./dez. 2017. p. 522-523. 38 Sem olvidar das particularidades dos sistemas jurídicos no mundo, o Programa das Nações Unidas para o Meio Ambiente aponta que em relação a justiciabilidade verifica-se que em comum o demandante deve ter o direito de ação (existência de uma controvérsia real e de normas que tutelam o direito envolvido) para que apresente o caso e a resolução judicial não deve violar as divisões funcionais entre os poderes legislativo, executivo e judiciário. PROGRAMA DE LAS NACIONES UNIDAS PARA EL MEDIO AMBIENTE. El estado del litigio en materia de cambio climático: una revisión global. Nairobi: División Jurídica ONU Medio Ambiente, mayo 2017. p. 27-30.
}

buscam, com a propositura da ação (i), a compensação ${ }^{39}$ pelos prejuízos que as mudanças climáticas causaram ou (ii) a maior prevenção ou redução do aquecimento global. ${ }^{40} \mathrm{E}$ os potenciais demandados (réus), geralmente, pertencem a um desses grupos:

(1) entidades que queimam fóssil no processo de fornecimento de um produto ou serviço (por exemplo, fornecedores de eletricidade); (2) entidades que fornecem combustíveis fósseis (por exemplo, companhias petrolíferas); (3) entidades que criam produtos que queimam combustíveis fósseis ou emitem gases de efeito estufa (por exemplo, fabricantes de carros e frigoríficos); e (4) governos e agências que não cumpram as obrigações ambientais. ${ }^{41}$

Ponto fulcral envolvendo a litigância climática é o nexo causal. Nesse contexto, destaca-se a importância da prova documental e técnica, pois a litigância climática requer um conjunto probatório confiável que consiga demonstrar ou correlacionar que o demandado contribuiu, significativamente, com o aquecimento global e, por conseguinte, com os danos/prejuízos suportados ou em risco pela demandante. Por isso, esse tipo de ação tem estreita relação com pesquisas científicas, como os Relatórios do IPCC, que acompanham a influência antropogênica nas mudanças climáticas.

Conforme Banda e Fulton, nota-se, nos tribunais nacionais, que os litígios climáticos estão estendendo a abordagem. A discussão vai além dos limites tradicio-

39 Às vezes, há nas demandas climáticas que visam à compensação relação com responsabilidade civil (frisa-se extracontratual), nesse sentido, Carvalho projeta que o instituto poderá passar por inovações, como "tratamento de danos massivos, teoria das probabilidades em termos de nexo de causalidade, utilização de estudos científicos como prova indiciária, entre outros." Segundo autor, a Teoria das Probabilidades é "uma teoria da causalidade sensível às informações probabilísticas acerca das possíveis causas do dano. Há, assim, a atribuição de profunda relevância jurídica para as prováveis consequências decorrentes de determinadas atividades, atenuando a carga probatória necessária para a caracterização da causalidade jurídica." CARVALHO, Délton Winter de. Gestão jurídica ambiental. São Paulo: Revista dos Tribunais, 2017. p. 337.

40 SMITH, Joseph; SHEARMAN, David. An introduction to climate change litigation. In: Climate change litigation. Australia: Presidian Legal Publications, 2006. cap. 1. p. 12-15.

${ }^{41}$ Versão original: "(1) entities that burn fóssil in the course of providing a product or service (eg. electricity suppliers); (2) entities that supply fóssil fuels (eg. oil companies); (3) entities that create products that burn fóssil fuels or otherwise emit greenhouse gases (eg. car and fridge manufacturers); and (4) governments and agencies that fail to comply with environmental obligations." SMITH, Joseph; SHEARMAN, David. An introduction to climate change litigation. In: Climate change litigation. Australia: Presidian Legal Publications, 2006. cap. 1. p. 17. 
nais do litígio ambiental $(v \cdot g$. poluição dos recursos naturais, avaliações de impacto ambiental) a fim de incluir questões variadas relacionadas (in)diretamente com as mudanças climáticas $(v \cdot g$. direito das gerações futuras, direito fundamental à vida, regulamentação das zonas de resiliência climática). Nesse sentido, os autores categorizam as disputas climáticas como:

(a) litígios envolvendo medidas de mitigação esforços destinados a reduzir ou prevenir emissões de gases de efeito estufa (GEEs), e (b) litígios envolvendo medidas de adaptação ao clima esforços projetados para construir resiliência e reduzir os impactos negativos das mudanças climáticas nas comunidades e ecossistemas. ${ }^{42}$

Inequívoco o estrito da matéria discutida em litígios climáticos, com aqueles caracterizados como ambientais. Dado que a litigância climática tem por cerne impulsionar os atores (nacionais e internacionais, públicos e privados) a adotarem medidas eficazes e efetivas contra o aumento da temperatura global, em razão da emissão antropogênica de gases de efeito estufa, bem como para a mitigação e adaptação às mudanças climáticas. Ou seja, há uma relação direta na obrigação dos atores em manter e preservar o meio ambiente sadio, seja por imposição legal, administrativa ou judicial. Desse modo, o que diferencia uma demanda ambiental de uma demanda climática?

Conforme Smith e Sheraman, há duas principais características que distinguem a litigância climática dos demais tipos de litígios, "em primeiro lugar, a cadeia causal envolvida é significativamente mais longa e complexa e, em segundo lugar, os tipos de danos causados são consideravelmente mais generalizados." ${ }^{\text {43 }}$ (Tradução nossa). Logo, a causalidade se prolonga no tempo, que pode ou não ter um evento extremo (v.g. Furacão Katrina, branqueamento dos corais), e os prejuízos e danos causados

\footnotetext{
42 Versão original: “(a) litigation involving climate mitigation measures - efforts designed to reduce or prevent emissions of greenhouse gases (GHGs), and (b) litigation involving climate adaptation measures - efforts designed to build resilience and reduce the negative impacts of climate change on communities and ecosystems." BANDA, Maria L.; FULTON, C. Scott. Litigating climate change in national courts: recent trends and developments in global climate law. Environmental Law Reporter, Washington, v. 47, p. 10121-10134, jan. 2017. Disponível em: https://www.eli.org/sites/default/files/ elr/featuredarticles/47.10121.pdf. Acesso em: 02 jan. 2019. p. 10121.

43 Versão original: "firsty, the causal chain involved is significantly longer and more complex and, secondly, the types of harm caused are considerably more widespread." SMITH, Joseph; SHEARMAN, David. An introduction to climate change litigation. In: Climate change litigation. Australia: Presidian Legal Publications, 2006. cap. 1. p. 11.
}

atingem um extenso grupo de pessoas e ambiente $(v . g$. população americana, recifes de corais em Fernando de Noronha).

Nesse sentido, inspirado em Robert Verchick, Carvalho adiciona como característica da litigância climática o distanciamento geográfico entre as atividades e os resultados lesivos.
As dimensões difusas das mudanças climáticas e dos diversos tipos de desastres ambientais impõem a reconfiguração das tradicionais noções de tempo e espaço, sendo passível a demonstração do nexo causal sempre que houver a condição de demonstrar a previsibilidade e a causa determinante. ${ }^{44}$

Os Estados Unidos da América concentram o maior número de demandas judiciais em matéria climática do que em qualquer outro país e, mesmo no caso de serem contabilizadas todas essas demandas fora de sua jurisdição, elas não conseguem alcançar seu patamar quantitativo. O Banco de Dados de Litigância Climática (Climate Change Litigation Databases), criado em 2007 no projeto conjunto entre o Sabin Center for Climate Change Law da Columbia Law School e o escritório de advocacia internacional Arnold \& Porter, contabilizou, até o mês de dezembro de 2018, 978 cases $^{45}$ envolvendo mudança climática somente nos Estados Unidos. ${ }^{46}$

Desde 2011, o grupo responsável pelo Banco de Dados de Litigância Climática começou também a catalogar os casos de litigância climática fora da jurisdição norte-americana e, até dezembro de 2018, verificou-se a existência de 275 cases. As jurisdições dos países e órgãos internacionais não norte-americanos e, respectivamente, a quantidade de cases atualmente catalogados neste estudo, são: Austrália, 97; Bélgica, 1; Canadá, 15; República Checa, 1; União Europeia, 41; Alemanha, 5; Índia,

44 CARVALHO, Délton Winter de. Gestão jurídica ambiental. São Paulo: Revista dos Tribunais, 2017. p. 337-338.

45 Os coordenadores do projeto advertem que o termo "cases", na tabela de litígios climáticos, compreende ações e processos judiciais e quase-judiciais administrativos, petições de regulamentação, pedidos de reconsideração de regulamentos, avisos de intenção de processar e intimações. Ademais, um único caso pode incluir outras queixas ou petições que foram consolidadas, bem como ter inclusas outras decisões nos níveis de apelação e avaliação. SABIN CENTER FOR CLIMATE CHANGE LAW. Climate change litigation databases. New York: Columbia Law School; Arnold \& Porter Kaye Scholer LLP, 2019. Disponível em: http://climatecasechart.com/. Acesso em: 15 jan. 2019.

46 SABIN CENTER FOR CLIMATE CHANGE LAW. Climate change litigation databases. New York: Columbia Law School; Arnold \& Porter Kaye Scholer LLP, 2019. Disponível em: http://climatecasechart.com/. Acesso em: 15 jan. 2019. 
2; Indonésia, 1; Países Baixos, 1; Nigéria, 1; Paquistão, 2; Polônia, 1; Espanha, 13; Suíça, 1; Ucrânia, 2; Áustria, 1; Brasil, 4; Colômbia, 2; Equador, 1; França, 4; Grécia, 0; Irlanda, 2; Micronésia, 1; Nova Zelândia, 17; Noruega, 1; Filipinas, 1; África do Sul, 3; Suécia, 1; Uganda, 1; Reino Unido, 47; Comité Europeu dos Direitos Sociais, 1; Corte Interamericana de Direitos Humanos, 2; Convenção-Quadro das Nações Unidas sobre Mudança do Clima, 1; Comissão Interamericana de Direitos Humanos, 1; Tribunal Internacional de Justiça, $1 .{ }^{47}$

Dado o exponencial número de cases climáticos norte-americanos, essa situação reflete a quantidade de centros de estudos de referência e prática forense sobre litígio de mudança climática. Na maioria das jurisdições não norte-americanas, elas ainda estão começando a incorporar o assunto no sistema jurídico e nas pesquisas cientificas.

Logo, sem olvidar das diferenças institucionais, legais e jurídicas entre os países, tendo em vista a experiência e a multiplicidade de abordagens, os precedentes que inspiram e instruem os processos de litigância climática e as pesquisas sobre a matéria no mundo se reportam, corriqueiramente, à jurisdição norte-americana.

Carvalho elenca como principais cases de litigância climática nas Cortes norte-americanas: (i) Connecticut $v$. American Electric Power, (ii) Comer v. Murphy Oil; (iii) California v. General Motors Corporation. ${ }^{48}$ Importante advertir que referidos cases fazem parte de uma primeira geração de litigância climática, logo torna-se extremamente relevante compreendê-los haja vista que externalizam as discussões introdutórias desta estratégia judicial de combate ao aquecimento global. Atualmente ${ }^{49}$, outros

47 SABIN CENTER FOR CLIMATE CHANGE LAW. Climate change litigation databases. New York: Columbia Law School; Arnold \& Porter Kaye Scholer LLP, 2019. Disponível em: http://climatecasechart.com/. Acesso em: 15 jan. 2019.

48 Vide CARVALHO, Délton Winter de. Gestão jurídica ambiental. São Paulo: Revista dos Tribunais, 2017.

CARVALHO, Délton Winter de. Uma incursão sobre a litigância climática: entre mudança climática e responsabilidade civil. In: MIRANDA, Jorge; GOMES, Carla Amado (coord.). Diálogo ambiental, constitucional e internacional. Lisboa: Faculdade de Direito de Lisboa; OH! Multimédia, 2017. v. 6. p. 95-118. Disponível em: http://www. icjp.pt/sites/default/files/publicacoes/files/ebook_dialogoambiental_6_3-18.pdf. Acesso em: 28 jan. 2019.

49 Embora não pertença a jurisdição norte-americana, mostra-se oportuno evidenciar o case Urgenda Foundation v. The State of the Netherlands. No dia 09 de outubro de 2018, o Tribunal de Apelação de Haia confirmou a decisão do Tribunal Distrital, concluindo a favor do pleito da Urgenda Fundation, fundação ambiental holandesa que também representava 886 indivíduos, contra o governo holandês cases que se destacam são (iv) Massachusetess v E.P.A, (v) Juliana $v$. United States.

No ano de 2004, 8 Estados e a cidade de Nova York ajuizaram ação contra American Electric Power, American Electric Power Service, Southern Company, TVA, Xcel Energy, Cinergy Corp., para que elas limitassem a emissão de gases de efeito estufa relativos à geração de energia elétrica pela queima de combustíveis fosseis, dado que os réus estavam contribuindo para o aquecimento global, resultando em incômodo público decorrente da mudança climática. O case (i) Connecticut $v$. American Electric Power foi rejeitado, em primeira instância (2005), sob a alegação de que as reivindicações eram questões políticas que não deveriam ser resolvidas pelo judiciário. O Tribunal de Apelação do Segundo Circuito reverteu a decisão (2009) ponderando pela legitimidade dos autores e da demanda. Em 2011, a Suprema Corte norte-americana extinguiu a ação, pois entendeu que não caberia ao judiciário decidir de forma a regulamentar a emissão dos gases de efeito estufa, uma vez que tal atribuição foi destinada pelo Congresso ao EPA..$^{50}$

para que ele se empenhasse mais na prevenção da mudança climática global. Ou seja, a questão não estava no reconhecimento de que o Estado precisaria empreender esforços para reduzir a emissão de gases de efeito estufa antropogênicos, mas sim no ritmo ou nível de empenho que o mesmo deveria ter nessas medidas de redução e, por conseguinte, de mitigação das mudanças climáticas. A promessa do Estado Holandês de reduzir em $17 \%$ as emissões de gases de efeito estufa antropogênicos até 2020 apresentava-se insuficiente para combater o aquecimento global. Isso porque a Corte concluiu que a meta de redução holandesa estava "abaixo do padrão considerado necessário pela ciência climática e pela política climática internacional, o que significa que, para evitar mudanças climáticas perigosas, os países do Anexo I [do Protocolo de Quito] (incluindo os Países Baixos) devem reduzir as emissões de gases de efeito estufa em 25\% a $40 \%$ para alcançar a meta de $2^{\circ} \mathrm{C}$." Assim a Corte determinou que os Países Baixos deverão limitar as emissões desses gases em pelo menos 25\% abaixo dos níveis de 1990 até o final de 2020. O governo holandês anunciou que pretende recorrer da decisão.

Versão original: "below the standard deemed necessary by climate science and the international climate policy, meaning that in order to prevent dangerous climate change Annex I countries (including the Netherlands) must reduce greenhouse gas emissions by $25-40 \%$ by 2020 to realise the $2^{\circ} \mathrm{C}$ target". SABIN CENTER FOR CLIMATE CHANGE LAW. Climate change litigation databases. New York: Columbia Law School; Arnold \& Porter Kaye Scholer LLP, 2019. Disponível em: http:/ / climatecasechart.com/. Acesso em: 15 jan. 2019. Urgenda Foundation v. The State of the Netherlands, C/09/456689/HA ZA 13-1396 (24 June 2015). Hague District Court.

50 Connecticut v. American Elec. Power Co. (AEP), 406 F. Supp. 2d 265, 35 ELR 20186 (S.D.N.Y. 2005).

SABIN CENTER FOR CLIMATE CHANGE LAW. Climate change litigation databases. New York: Columbia Law School; Arnold \& Porter Kaye Scholer LLP, 2019. Disponível em: http://climatecasechart.com/. Acesso em: 15 jan. 2019. 
Inconformados com as decisões proferidas pelo Tribunal Distrital do Distrito Sul do Mississippi (2007), Tribunal de Apelação do Quinto Circuito (2009) e Suprema Corte dos Estados Unidos (2011) que não deram procedência ao pleito, o grupo de 11 residentes e proprietários do Mississippi apresentou, no ano de 2011, uma nova ação coletiva no Tribunal Distrital, contra 11 companhias petrolíferas, 66 companhias carvoeiras e 3 companhias químicas. Muito similar a primeira ação proposta em meados de 2005, no case (ii) Comer v. Murphy OiF', a demanda consistia em responsabilizar os réus pelos inúmeros prejuízos e danos que os demandantes tiveram com a ocorrência do furacão Katrina e das mudanças climáticas. Os demandantes alegam que os réus, no exercício de suas atividades industriais, contribuíram para o aquecimento global, refletindo a intensificação do furacão Katrina, em causas de incômodo público e privado, trespasse e negligência de ações sob a lei do Mississipi. A ação foi igualmente extinta em primeira (2012) e segunda instância (2013). ${ }^{52}$

O case (iii) California v. General Motors Corporation iniciou em 2006 quando o Estado da Califórnia ajuizou a ação no Tribunal Distrital do Norte da Califórnia contra as empresas General Motors Corporation, Toyota Motor North America, Ford Motor Company, Honda North America, Chrysler Motors Corporation, Nissan North America. A demandante alega que as empresas automobilísticas eram responsáveis pelos prejuízos que o Estado e a população californiana estavam sofrendo em decorrência das mudanças climáticas, tendo em vista que os veículos produzidos pelos réus emitiam gases de efeito estufa que contribuíam substancialmente para o aquecimento global. No ano seguinte, o Tribunal entendeu por conceder a motion (moção) das empresas, pontuando que as formulações levantadas no pleito eram "questões políticas" e que pela doutrina constitucional da separação dos poderes, deveriam ser analisadas pelo Congresso e pelo Presidente. Como na Administração Obama, verificavam-se mudanças políticas progressivas nas questões envolvendo os gases de efeito estufa, no ano de 2009, a Procuradoria-Geral da Califórnia desis-

\footnotetext{
51 Ressalta Carvalho que esta nova demanda também é conhecida como Comer II.

52 Comer v. Murphy Oil USA, No. 05-cv-436, 2007 WL 6942285 (S.D. Miss. Aug. 30, 2007).

SABIN CENTER FOR CLIMATE CHANGE LAW. Climate change litigation databases. New York: Columbia Law School; Arnold \& Porter Kaye Scholer LLP, 2019. Disponível em: http://climatecasechart.com/. Acesso em: 15 jan. 2019.
}

tiu, voluntariamente, de recorrer da decisão judicial. ${ }^{53}$

Em 2007 iniciou o case (iv) Massachusetess v Environmental Protection Agency (E.P.A), no qual 12 estados, 3 cidades, 11 organizações não-governamentais e 2 organizações privadas, peticionaram contra a Environmental Protection Agency (EPA). Os peticionantes alegam que a omissão da agência de proteção ambiental para regulamentação sobre os gases de efeito estufa (frisa-se, estabelecer os padrões de emissão), em conformidade com a Lei do ar limpo (Clean Air Act) estaria contribuindo com o aquecimento global. Considerando-se os estudos científicos que atestavam os prejuízos potenciais aos demandantes com a intensificação das mudanças climáticas (ressalta-se o aumento do nível do mar), a Suprema Corte norte-americana deu procedência em favor dos peticionantes e obrigou que a EPA regulamentasse a matéria. ${ }^{54}$ Segundo Carvalho, "este precedente tem sido visto como uma possível mudança na percepção judicial de legitimidade, dos riscos de danos catastróficos e da causalidade, fazendo menção expressa a um padrão de probabilidade". 55

Atualmente, um dos casos mais emblemáticos em solo norte-americano e fora dele é (v) Juliana v. United States. O Tribunal Distrital de Oregon, divisão Eugene, recebeu em 2015 a petição conjunta de 21 crianças e jovens norte-americanos, da organização sem fins lucrativos Earth Guardian e das "gerações futuras" (Future Generations), esta representada pelo Dr. James Han$\operatorname{sen}^{56}$. Como parte contrária consta os Estados Unidos da América, o presidente e vários cargos e agências da administração do governo federal (gestão Barack Oba-

53 California v. General Motors Corp., No. C06-05755 MJJ, 2007 WL 2726871, 37 ELR 20239 (N.D. Cal. Sept. 17, 2007)

SABIN CENTER FOR CLIMATE CHANGE LAW. Climate change litigation databases. New York: Columbia Law School; Arnold \& Porter Kaye Scholer LLP, 2019. Disponível em: http://climatecasechart.com/. Acesso em: 15 jan. 2019.

54 Massachusetts v. EPA, 549 U.S. 497, 525-26, 37 ELR 20075 (2007). SABIN CENTER FOR CLIMATE CHANGE LAW. Climate change litigation databases. New York: Columbia Law School; Arnold \& Porter Kaye Scholer LLP, 2019. Disponível em: http://climatecasechart.com/. Acesso em: 15 jan. 2019.

55 CARVALHO, Délton Winter de. Uma incursão sobre a litigância climática: entre mudança climática e responsabilidade civil. In: MIRANDA, Jorge; GOMES, Carla Amado (coord.). Diálogo ambiental, constitucional e internacional. Lisboa: Faculdade de Direito de Lisboa; OH! Multimédia, 2017. v. 6. p. 95-118. Disponível em: http://www. icjp.pt/sites/default/files/publicacoes/files/ebook_dialogoambiental_6_3-18.pdf. Acesso em: 28 jan. 2019.p. 60.

56 Cientista do clima e ex-diretor do Instituto Goddard de Estudos Espaciais da NASA. 
ma e passadas), tendo em vista o fracasso dos réus na redução das emissões de dióxido de carbono. Os peticionários alegam que os réus, ao permitirem a produção e consumo de combustíveis fosseis em níveis perigosos, prejudicaram o "sistema climático da nação", o qual é essencial para exercícios dos direitos constitucionais de vida, liberdade e propriedade. Diante disso, o pleito consiste em que o Tribunal obrigue os réus a tomarem medidas de redução da emissão de dióxido de carbono, para que as concentrações atmosféricas de gás carbônico não excedam 350 partes por milhão até 2100 . O processo ainda está sob julgamento. ${ }^{57}$

Em estudo conjunto feito pelo Programa das $\mathrm{Na}$ ções Unidas para o Meio Ambiente com o Sabin Center for Climate Change Law da Columbia Law School, foi verificado que pelas recentes demandas e decisões judiciais relacionadas com as alterações no clima existem 5 tendências aos propósitos perseguidos pela litigância climática, são eles:
1) Exigir que os governos cumpram com seus compromissos legislativos e de políticas; 2) [Vincular] o impacto da extração de recursos com a mudança climática e a resiliência; 3) Estabelecer que emissões particulares são a causa imediata de impactos adversos das mudanças climáticas; 4) Estabelecer responsabilidades pelas falhas (ou esforços) de adaptação a mudança climática; 5) Aplicar a doutrina do fideicomisso público a mudança climática ${ }^{58}$. (Tradução nossa).

Para os próximos anos, o referido estudo apontou como tendências emergentes na litigância climática:

1) um crescente número de casos relativos a população que precisa emigrar em busca de realocação temporária ou permanente fora de seu país ou região de origem, devido, pelo menos em parte, a mudança climática [refugiados ambientais];

\footnotetext{
57 Juliana v. United States, No. 6:15-CV-01517-TC, 2016 WL 6661146, 46 ELR 20175 (D. Or. Nov. 10, 2016).

SABIN CENTER FOR CLIMATE CHANGE LAW. Climate change litigation databases. New York: Columbia Law School; Arnold \& Porter Kaye Scholer LLP, 2019. Disponível em: http://climatecasechart.com/. Acesso em: 15 jan. 2019.

58 Versão original: “1) Exigir que los gobiernos cumplan con sus compromissos legislativos y de políticas; 2) El impacto de la extracción de recursos y su vínculo con el cambio climático y la resiliencia; 3) Establecer que emisiones particulares son la causa inmediata de impactos adversos del cambio climáticos; 4) Establecer responsabilidades por las fallas (o esfuerzos) de adaptación al cambio climático; 5) Aplicar la doctrina del fideicomiso público al cambio climático." PROGRAMA DE LAS NACIONES UNIDAS PARA EL MEDIO AMBIENTE. El estado del litigio en materia de cambio climático: una revisión global. Nairobi: División Jurídica ONU Medio Ambiente, mayo 2017. p. 14.
}

e 2) maior número de litígios relacionados com a mudança climática no Sul mundial. ${ }^{59}$ (Tradução nossa).

Outra tendência apontada por Peel e Osofsky é a dos peticionários, em litígios climáticos, utilizarem como base argumentativa a violação aos direitos humanos ${ }^{60}$ no contexto de mudanças climáticas e a receptividade dos Tribunais utilizarem tais direitos como ferramenta interpretativa na litigância climática. Não obstante os Tribunais já decidirem acerca das mudanças climáticas sob contornos de direitos humanos, o sucesso desse argumento tem sido mais elusivo (vago). ${ }^{61}$

Todavia ao analisarem alguns cases climáticos nos quais foram desenvolvidos argumentos baseados em violações aos direitos humanos, os referidos autores observaram uma mudança, uma "virada", na proemi-

59 Versão original: “1) un creciente numero de casos relativos a poblacion que tiene que emigrar y buscan reubicacion temporal o permanente fuera de su pais o region de origen, debido, por lo menos en parte, al cambio climatico, y 2) mayor numero de litigaciones relacionadas con el cambio climatico en el Sur mundial." PROGRAMA DE LAS NACIONES UNIDAS PARA EL MEDIO AMBIENTE. El estado del litigio en materia de cambio climático: una revisión global. Nairobi: División Jurídica ONU Medio Ambiente, mayo 2017. p. 25. 60 A estratégia processual argumentativa pautada na violação ao sistema climático sadio derivado do mandamento universal de proteção ao meio ambiente inserto na gama de direitos humanos fundamentais encontra desafios substanciais. Isso porque, precede à discussão inter partes o fato de que "a consideração do direito ao meio ambiente sadio como um direito humano, em sede global e regional, ou como um direito fundamental, pelos Estados, ainda encontra óbices de efetividade. As inter-relações entre os sistemas internos e internacionais, que deveriam sinergicamente promovê-lo, encontram obstáculos que se entrecruzam centrípeta e centrifugamente, vale dizer, da comunidade internacional para os Estados e destes para aquela." Mas há de se ressaltar que "direito e política ambientais tendem a avançar, quando há o envolvimento da sociedade civil e, ao mesmo tempo, quando os Estados se propõem a colaborar mais do que a competir. Os dois fatores se estimulam reciprocamente e são os instrumentos mais eficazes para superar os óbices, as forças dissipadoras de integração dos sistemas de proteção.” Esse envolvimento mútuo da sociedade civil e dos Estados nacionais na promoção e proteção do meio ambiente e sistema climático equilibrados podem ser exteriorizados, por exemplo, pela via das demandas climáticas e suas repercussões na governança (ambiental, regional e global). SAMPAIO, José Adércio Leite; COSTA, Beatriz Souza. As complicadas inter-relações entre os sistemas internos e internacionais de proteção do direito ao meio ambiente sadio. Revista de Direito Internacional, Brasília, v. 12, n. 2, p. 785-803, 2015. Disponível em: https://www.publicacoesacademicas.uniceub.br/rdi/article/ view/3748/pdf. Acesso em: 07 jul. 2019. p. 798.

${ }_{61}$ PEEL, Jacqueline; OSOFSKY, Hari M. A rights turn in climate change litigation? Transnational Environmental Law, Cambridge, v. 7, n. 1, p. 37-67, mar. 2018. Disponível em: https://www.cambridge. org/core/journals/transnational-environmental-law/article/rightsturn-in-climate-change-litigation/0E35456D7793968F37335429C1 163EA1. Acesso em: 27 jan. 2019. p. 38-39; 60-67. 
nentemente alegação de os governos não levarem em consideração e, de forma adequada, a mudança do clima em suas decisões (modo mais convencional de litígio climático). Essa abordagem vem de encontro com a crescente atenção internacional na relação entre direitos humanos e mudanças climáticas (endossado no Acordo de Paris). A virada argumentativa na litigância climática, baseada na violação dos direitos humanos, impacta o direcionamento da atenção pública e política às consequências prejudiciais que as mudanças climáticas podem causar à humanidade. O que pode revelar-se, em última instância, ser uma abordagem mais expressiva para a motivação de uma ação forte à solução do problema, do que argumentos científicos e técnicos. ${ }^{62}$

Dada a amplitude, complexidade e autoridade que a questão climática impõe, reforça-se a necessidade de os Poderes Legislativo e Executivo desempenharem com energia suas atribuições e, caso não o façam, valioso torna-se o estímulo (obrigação) propiciado pelo Poder Judiciário.

Aliás, no recente trabalho publicado por McCormick et. al. no qual foram analisadas decisões judiciais norte-americanas, os pesquisadores apontaram que a litigância climática pode ser uma abordagem eficaz para proteger a saúde e bem-estar humanos no contexto das mudanças climáticas e insuficiência nas ações legislativa e executiva.

Os Tribunais podem desempenhar um papel fundamental na condução da mudança, exigindo que as agências [governamentais] levem em consideração as mudanças climáticas sob leis como do NEPA [National Environmental Policy Act e leis estaduais similares. ${ }^{63}$

Portanto, a litigância climática é uma estratégia promissora para compelir os grandes causadores do aquecimento global e, principalmente, os responsáveis pela

62 PEEL, Jacqueline; OSOFSKY, Hari M. A rights turn in climate change litigation? Transnational Environmental Law, Cambridge, v. 7, n. 1, p. 37-67, mar. 2018. Disponível em: https://www.cambridge. org/core/journals/transnational-environmental-law/article/rightsturn-in-climate-change-litigation/0E35456D7793968F37335429C1 163EA1. Acesso em: 27 jan. 2019. p. 38-39; 60-67.

${ }^{63}$ Versão original: "Courts can play a key role in driving change by requiring agencies to take climate change into account under laws such as NEPA and similar state laws." MCCORMICK, Sabrina; SIMMENS, Samuel J.; GLICKSMAN, Robert; PADDOCK, LeRoy; KIM, Daniel; WHITED, Brittany. The role of health in climate litigation. American Journal of Public Health: AJPH Law \& Ethics, Washington, v. 108, n. S2, suppl. 2, p. S104-S108, apr. 2018. Disponível em: https://ajph.aphapublications.org/doi/pdf/10.2105/ AJPH.2017.304206. Acesso em: 03 jan. 2019. regulamentação e fiscalização das emissões de gases de efeito estufa antropogênicos a enfrentarem, efetivamente, e eficazmente as mudanças climáticas.

\section{Considerações finais}

A intensificação na emissão de gases de efeito estufa pelas atividades humanas, ao longo dos séculos (tendo como marco inicial a revolução industrial), interferiu no equilíbrio da atmosfera terrestre, causando grandiosos e prolongados danos à biosfera e a própria existência digna do ser humano.

A regulamentação e fiscalização da emissão de gases de efeito estufa antropogênicos deve ser empreendido pelos Poderes Executivo e Legislativo, pois, como representantes legítimos dos interesses do povo, no âmbito de suas funções institucionais, assegurar o bem-estar coletivo não é uma escolha, mas sim uma obrigação. E, considerando todas as conquistas de direitos humanos, função social e ambiental da empresa, e compreensão da finitude dos recursos naturais, impossível que na atualidade o setor empresarial/industrial mantenha o cabresto do capitalismo selvagem.

Não obstante as experiências daqueles que já foram lesionados pelas mudanças climáticas, os relatos dos que estão sob risco e os estudos científicos praticamente unânimes sobre o aquecimento global antropogênico e o papel do Poder Público e das grandes empresas para minorar a situação, se tem vivenciado medidas pouco enérgicas para a solução do problema (frisa-se: de escala mundial e intergeracional).

Para romper com a omissão e comedimento relativo à redução da emissão de gases de efeito estufa a fim de que o aquecimento global não alcance $1,5^{\circ} \mathrm{C}$ acima dos níveis pré-industriais e sejam realmente implementadas e aprimoradas medidas de mitigação e adaptação a mudança no clima (inclusive deferindo maior atenção àqueles em vulnerabilidade social), a litigância climática apresenta-se como uma estratégia promissora e esperançosa.

A litigância climática é uma abordagem em ascensão no cenário internacional, mas, nos Estados Unidos da América, já apresenta uma tradição e precedentes que inspiram e influenciam os outros sistemas jurisdicionais do planeta. Diante dos impactos potencialmente irre- 
paráveis, causados pelas mudanças climáticas, colocar o clima no centro da discussão judicial demonstra a importância e urgência com que o problema precisa ser enfrentado.

As decisões judiciais na litigância climática robustecem o papel e a responsabilidade dos atores cruciais à emissão de gases de efeito estufa antropogênicos para alterarem a lógica e o modus operandi descomprometido com as causas globais e perpetuação digna dos seres vivos. De nada adianta o progresso (econômico, cientifico e tecnológico) se não existir um mundo em que se possa usufruí-lo.

A procedência do pleito em uma ação judicial climática trará resultados positivos de controle e responsabilização que extrapolam as partes envolvidas, tendo em vista a natureza pública da matéria. E, mesmo na negativa do pleito, a litigância climática repercute, politicamente, nas ações governamentais e privadas, bem como na atenção pública ao assunto, sendo um valoroso instrumento de governança e real mudança.

\section{Referências}

ACORDO DE PARIS, 2015. Disponível em: https:// nacoesunidas.org/wp-content/uploads/2016/04/ Acordo-de-Paris.pdf. Acesso em: 02 jan. 2019.

BERNARDO, Vinicius Lameira. Mudanças climática: estratégia de litigância e o poder do judiciário no combate às causas do aquecimento global no contexto brasileiro. Revista de Direito Ambiental, Porto Alegre, a. 22, v. 88, p. 517-548, out./dez. 2017.

BANDA, Maria L.; FULTON, C. Scott. Litigating climate change in national courts: recent trends and developments in global climate law. Environmental Law Reporter, Washington, v. 47, p. 10121-10134, jan. 2017. Disponível em: https://www.eli.org/sites/default/files/elr/featuredarticles/47.10121.pdf. Acesso em: 02 jan. 2019.

BIATO, Márcia Fortuna. Convenção-quadro das Nações Unidas sobre mudança do clima. Revista de Informação Legislativa, Brasília, a. 42, n. 166, p. 233-252, abr./ jun. 2005. Disponível em: http://egov.ufsc.br/portal/ sites/default/files/anexos/22129-22130-1-PB.pdf. Acesso em: 26 fev. 2019.
BOIXAREU, Isabel Vilaseca; CALVÓ, Jordi Serra. Litigación climática y separación de poderes: uma aproximación a la cuestión a través de decisiones judiciales de los Estados Unidos. Revista Catalana de Dret Ambiental, Catalunya, v. 9, n. 2, p. 01-42, 2018. Disponível em: https://revistes.urv.cat/index.php/rcda/article/ view/2182/2452. Acesso em: 26 jan. 2019.

BRASIL, Alexandre Luis Junges; BRASIL, Neusa Teresinha Massoni. O consenso científico sobre aquecimento global antropogênico: considerações históricas e epistemológicas e reflexões para o ensino dessa temática. Revista Brasileira de Pesquisa em Educação em Ciências, Belo Horizonte, v. 18, n. 2, p. 455-491, maio/ago. 2018. Disponível em: https://seer.ufmg.br/index.php/rbpec/ article/view/10345. Acesso em: 02 jan. 2019.

CARVALHO, Délton Winter de. Gestão jurídica ambiental. São Paulo: Revista dos Tribunais, 2017.

CARVALHO, Délton Winter de. Uma incursão sobre a litigância climática: entre mudança climática e responsabilidade civil. In: MIRANDA, Jorge; GOMES, Carla Amado (coord.). Diálogo ambiental, constitucional e internacional. Lisboa: Faculdade de Direito de Lisboa; OH! Multimédia, 2017. v. 6. p. 95-118. Disponível em: http:/ /www.icjp.pt/sites/default/ files/publicacoes / files/ebook_dialogoambiental_6_3-18.pdf. Acesso em: 28 jan. 2019.

CONTIPELLI, Ernani de Paula. Política internacional climática: do consenso científico à governança global. Direito e Desenvolvimento, João Pessoa, v. 9, n. 2, p. 8394, ago./dez. 2018. Disponível em: https://periodicos. unipe.br/index.php/direitoedesenvolvimento/article/ view/644. Acesso em: 31 jan. 2019.

CONVENÇÃO SOBRE MUDANÇA DO CLIMA, 1992. Disponível em: https://cetesb.sp.gov.br/procli$\mathrm{ma} / \mathrm{wp}$-content/uploads/sites/36/2014/08/convencaomudancadoclima.pdf. Acesso em: 02 jan. 2019.

FARBER, Daniel A.; CARLARNE, Cinnamon P. The international climate change regime. In: Climate change law. St. Paul: Foundation Press, 2018. cap. 3.

FONSECA, Fúlvio Eduardo. A convergência entre a proteção ambiental e a proteção da pessoa humana no âmbito do direito internacional. Revista Brasileira de Política Internacional, Rio de Janeiro, v. 50, n. 1, p. 121-138, 2007. Disponível em: http://www.scielo.br/pdf/rbpi/ v50n1/a07v50n1. Acesso em: 26 fev. 2019. 
INTERGOVERNMENTAL PANEL ON CLIMATE CHANGE (IPCC). Summary for policymakers. In: Special report: global warming of $1,5^{\circ} \mathrm{C}$. Geneva: World Meteorology Organization, 2018. Disponível em: https:// www.ipcc.ch/sr15/chapter/summary-for-policy-makers/. Acesso em: 29 jan. 2019.

MCCORMICK, Sabrina; SIMMENS, Samuel J.; GLICKSMAN, Robert; PADDOCK, LeRoy; KIM, Daniel; WHITED, Brittany. The role of health in climate litigation. American Journal of Public Health: AJPH Law \& Ethics, Washington, v. 108, n. S2, suppl. 2, p. S104S108, apr. 2018. Disponível em: https://ajph.aphapublications.org/doi/pdf/10.2105/AJPH.2017.304206. Acesso em: 03 jan. 2019.

NATIONAL AERONAUTICS AND SPACE ADMINISTRATION (NASA). Scientific consensus: Earth's climate is warming. California: Earth Science Communications Team at NASA's Jet Propulsion Laboratory; California Institute of Technology, 2019. Disponível em: https://climate.nasa.gov/scientific-consensus/. Acesso em: 27 fev. 2019.

NOBRE, C. A. Mudanças climáticas e o Brasil: contextualização. Parcerias Estratégicas, Brasília, v. 27, p. 7-17, 2008. Disponível em: http://seer.cgee.org.br/index. php/parcerias_estrategicas/article/viewFile/326/320. Acesso em: 30 jan. 2019.

PEEL, Jacqueline; OSOFSKY, Hari M. A rights turn in climate change litigation? Transnational Environmental Law, Cambridge, v. 7, n. 1, p. 37-67, mar. 2018. Disponível em: https://www.cambridge.org/core/ journals/transnational-environmental-law/article/ rights-turn-in-climate-change-litigation/0E35456D77 93968F37335429C1163EA1. Acesso em: 27 jan. 2019.

PROGRAMA DE LAS NACIONES UNIDAS PARA EL MEDIO AMBIENTE. El estado del litigio en materia de cambio climático: una revisión global. Nairobi: División Jurídica ONU Medio Ambiente, mayo 2017.

OBSERVATÓRIO DO CLIMA. Emissões de GEE no Brasil e suas implicações para politicas públicas e a contribuição brasileira para 0 Acordo de Paris: documento de análise 2018. Brasil, SEEG, 2018. Disponível em: http:// seeg.eco.br/wp-content/uploads/2018/08/RelatoriosSEEG-2018-Sintese-FINAL-v1.pdf. Acesso em: 31 jan. 2019.
OFFICE OF PLANNING AND RESEARCH (OPR). List of worldwide scientific organizations. California, 2019. Disponível em: http://www.opr.ca.gov/facts/list-ofscientific-organizations.html. Acesso em: 27 fev. 2019.

ORGANIZAÇÃO DAS NAÇÕES UNIDAS (ONU). Protocolo de Quioto, 1997. Disponível em: http://mudancasclimaticas.cptec.inpe.br/ rmclima/pdfs/Protocolo_Quioto.pdf. Acesso em: 02 jan. 2019.

ORGANIZAÇÃO DAS NAÇÕES UNIDAS (ONU). Conferência das Nações Unidas sobre mudança do clima. Brasil, 2018. Disponível em: https://nacoesunidas.org/ cop21/. Acesso em: 26 fev. 2019.

ORGANIZACIÓN METEOROLÓGICA MUNDIAL (OMM). Boletín de la OMM sobre los gases de efecto invernadero. n. 14. Genebra: OMM, 22 nov. 2018. Disponível em: https://library.wmo.int/index. php?lvl=notice_display\&id=6887\#.XFgD0VxKhPY. Acesso em: 04 jan. 2019.

SABIN CENTER FOR CLIMATE CHANGE LAW. Climate change litigation databases. New York: Columbia Law School; Arnold \& Porter Kaye Scholer LLP, 2019. Disponível em: http://climatecasechart.com/. Acesso em: 15 jan. 2019.

SAMPAIO, José Adércio Leite; COSTA, Beatriz Souza. As complicadas inter-relações entre os sistemas internos e internacionais de proteção do direito ao meio ambiente sadio. Revista de Direito Internacional, Brasília, v. 12, n. 2, p. 785-803, 2015. Disponível em: https:// www.publicacoesacademicas.uniceub.br/rdi/article/ view/3748/pdf. Acesso em: 07 jul. 2019.

SAINT-GENIÈS, Géraud de Lassus. Direito transnacional e mudanças climáticas. Revista de Direito Internacional, Brasília, v. 13, n. 3, p. 49-61, 2016. Disponível em: https://www.publicacoesacademicas.uniceub.br/rdi/ article/view/4377/pdf. Acesso em: 07 jul. 2019.

SMITH, Joseph; SHEARMAN, David. An introduction to climate change litigation. In: Climate Change Litigation. Australia: Presidian Legal Publications, 2006. cap. 1.

US NATIONAL ACADEMY OF SCIENCES; THE ROYAL SOCIETY. Climate change: evidence \& causes. Washington: National Academy of Sciences, 2014. Disponível em: https://www.nap.edu/read/18730/chapter/1. Acesso em: 27 fev. 2019. 


\section{Agradecimento}

O presente trabalho foi realizado com apoio da Coordenação de Aperfeiçoamento de Pessoal de Nível Superior - Brasil (CAPES) - Código de Financiamento 001. Programa de Excelência Acadêmica (Proex). 
Para publicar na Revista de Direito Internacional, acesse o endereço eletrônico www.rdi.uniceub.br ou www.brazilianjournal.org.

Observe as normas de publicação, para facilitar e agilizar o trabalho de edição. 